\title{
Consultancy to dairy farmers relating to animal health and herd health management on small- and medium-sized farms
}

\author{
H. Pothmann, ${ }^{\star}$ K. Nechanitzky, ${ }^{*}$ F. Sturmlechner, $†$ and M. Drillich ${ }^{\star 1}$ \\ ${ }^{*}$ Clinic for Ruminants, Section for Herd Health Management, Vetmeduni Vienna, 1210 Vienna, Austria \\ †Federation of Austrian Cattle Breeders, 1200 Vienna, Austria
}

\begin{abstract}
The objectives of this study were to obtain information about animal health challenges for dairy farmers of small- and medium-sized herds and about the fields in which consultancy services should be improved. The hyperlink to an internet-based survey was sent to 9,021 farmers in Austria. The survey included questions about the participants and their farms, about who is consulting with the farmers with regard to animal health, feeding, sire selection, construction of barns and animal husbandry, about animal health issues farmers find most challenging, and about their demands for improved consultancy services. The questionnaire was completed anonymously. Analyses were stratified by milk yield (categorized) and whether farmers worked full-time or part-time. The overall response rate was $11.3 \%(\mathrm{n}=1,018)$. The majority of farms kept less than 20 cows $(54.0 \%)$ or 20 to 50 cows $(40.1 \%)$. With regard to animal health, the veterinarian was the most important consultant for the majority of farmers (84.6\%). On issues related to feeding, sire selection, and stable construction, the veterinarian was seen as a less important consultant than specialists in these fields $(20.4,11.6$, and $7.9 \%$ suggested the veterinarian as an important consultant in these areas). The survey indicated that reproductive disorders, udder disease, poor conception rate, lameness, and calf diarrhea represent the most important challenges to farmers. Of these, concerns about calf diarrhea were affected by milk yield of the herds and management. More high- than low-yielding farms (11.7 vs. 6.4\%) and more full-time than parttime managed herds (9.6 vs.4.3\%) regarded calf diarrhea as an important problem. Farmers would welcome improved consultancy with regard to fertility, feeding, and sire selection. The results indicated which animal health issues farmers find particularly challenging and displayed which areas farmers require improved consultancy services. Veterinarians and organizations offering
\end{abstract}

Received August 13, 2013.

Accepted October 10, 2013.

${ }^{1}$ Corresponding author: marc.drillich@vetmeduni.ac.at consultancy should take the results into consideration in improving or adapting their advisory services.

Key words: survey, farmer, dairy herd management, consultancy

\section{INTRODUCTION}

In modern dairy farming, attention has shifted from the individual animal toward the herd, and most management decisions are made at the herd level (Noordhuizen and Metz, 2005; LeBlanc et al., 2006). Increased economic pressure is demanding excellent herd management, including aspects of feeding, animal husbandry, and sire selection. Dairy farmers are confronted every day with challenges regarding animal health and welfare (Kielland et al., 2010). Whereas some farmers focus mainly on high milk production, others concentrate on animal health, milk quality, or other issues (Bergevoet et al., 2004; Kristensen and Enevoldsen, 2008). Farmers' attitudes and characteristics influence their compliance to veterinary advice (Kielland et al., 2010). In addition, veterinarians are not always aware of the farmers' goals (Kristensen and Enevoldsen, 2008) and often have difficulties communicating their advice and adapting their advice to those goals (Jansen et al., 2010; Derks et al., 2012). Furthermore, the perception of hazards for disease differs from farmers to veterinarians, underlining that communication between them may be improved (Bergevoet et al., 2004). Good cooperation between farmers, veterinarians, and other organizations involved in livestock production is an important component in modern herd health management (Jansen et al., 2010; Derks et al., 2013).

Recent surveys have provided information on farmers' most challenging problems. Caraviello et al. (2006) showed that the majority of farmers are concerned about mastitis, dermatitis digitalis, and abortion. With regard to reproduction, most concerns are related to AI, low conception rate, and twin pregnancy. Another survey analyzed fresh cow management on German dairy farms, which included monitoring of the cows by the farmers and veterinarians and recording of health data (Heuwieser et al., 2010). Most farmers indicated 
that they had implemented some kind of fresh cow examination, but only $18.5 \%$ documented their observations. Only $39.0 \%$ of the farmers recorded postpartum disorders, most often cases of milk fever, retained placenta, left displacement of abomasum, and metritis (Heuwieser et al., 2010). A valid database, however, is essential for effective management decisions on modern dairy farms (Iwersen et al. 2012). The cited studies were mainly conducted on large dairy herds [e.g., the average herd size in the survey by Caraviello et al. (2006) was 613 cows]. Although herd size increases in most countries and is $>150$ cows per herd in the United States (Chase et al. 2006), many family farms with less than 50 cows still exist in North America and Europe (Drillich et al., 2007; Russell and Bewley, 2013). On small- and medium-sized dairy farms, however, most diseases and disorders are numerically rare events and can often not be used for valid analyses and risk assessment. Thus, collective databases might support farmers and veterinarians in their work. In Austria, a concept for recording animal health data, including diagnoses and treatments, was established in 2006 ("health monitoring in cattle") by the Federation of Austrian Cattle Breeders (FACB) in cooperation with several organizations involved in animal health (Egger-Danner et al., 2012).

Transfer of knowledge and exchange of information is crucial for the success of modern dairy farms (Chase et al., 2006). Knowledge can be achieved by the farmers themselves via continuing education or transferred to the farms by consultants of the dairy industry (e.g., extension professionals, veterinarians, and nutritionists; Russell and Bewley, 2011, 2013). In that context, the Internet has increasingly been incorporated in continuing education and transfer of knowledge (Chase et al. 2006; Kensinger and Muller, 2006).

The primary objective of this study was to obtain information about the animal health issues perceived as most challenging by famers and about farmers' needs for consultancy services from veterinarians and other advisors. The farmers' attitudes to continuing education programs and the transfer of knowledge were also of interest.

\section{MATERIALS AND METHODS}

\section{Survey}

The hyperlink to the survey was sent to a total of 9,021 farmers via an e-mail distribution list generated by FACB in cooperation with the regional Dairy Herd Improvement Service (Landeskontrollverband; DHIS). This e-mail was resent $3 \mathrm{wk}$ after the initial request to participate in the project. All farmers contacted were members of FACB and DHIS. The DHIS provides monthly milk record data, reproductive performance data (days to first service, days open, number of services), and data on previous treatments of the animals to the farmers.

The survey was online from October 5 to December 3,2011 . It contained a total of 25 questions, either multiple choice or binary. The questionnaire consisted of a general section and more specific sections related to animal health and consultancy. The questionnaire was completed anonymously and accessed via the Internet.

In the general section, the first questions were related to sex, age $(<30,30-50$, and $>50 \mathrm{y})$, and education (agricultural school, agricultural diploma, other). The following questions queried herd size $(<20,20-50$, and $>50$ cows $)$, average milk yield $(<6,000,6,000-8,000$, $8,000-10,000$, and $>10,000 \mathrm{~kg} /$ lactation), housing system (freestalls or tiestalls), and main breed (Simmental, Brown Swiss, Holstein Friesian, other). Further questions were related to management (full-time or parttime farmer), the frequency of visit by the veterinarian ( $\geq$ once per week, once per 2 wk, once per month, or $<$ once per month), and whether the farmer is member of the Austrian Animal Health Service (Österreichischer Tiergesundheitsdienst; AAHS) and participates in a program of the AAHS. The AAHS offers programs in which farmers can participate voluntarily with the aim to improve fertility, udder health, or fighting parasites. Participants of programs accept intensified diagnostics by veterinarians and in return receive reduced costs for analyses of milk and blood samples.

Further questions addressed who is consulting with the farmer with regard to animal health, feeding, sire selection, animal husbandry, and stable construction. These questions offered a selection of answers, including veterinarian, Chamber of Agriculture, FACB, regional DHIS, feeding enterprise, AAHS, university, private consultant (not local veterinarian), focus group, others, or nobody. In Austria, focus groups are groups of farmers with special interests (e.g., milk production, animal production, or breeding) who meet periodically to discuss problems and share experiences. In principal, farmers have access to all these consultants. No data, however, are available on how many farmers use the particular consultants.

The following section contained questions regarding health issues and diseases of cattle. Predetermined traits (e.g., mastitis, metabolic disorders, animal husbandry, and heat detection) had to be assigned to 1 out of 5 categories from "very large problem" to "no problem." Because only few answers were given in some categories, "very large problem" and "large problem" were combined into "large problem" when the answers were analyzed and stratified by farm characteristics (kind of 
management, milk yield). Moreover, the survey queried which fields the veterinarian, beside his practical work, is an important consultant for the farmer (i.e., feeding, udder health, sire selection, claw trimming, stable construction and animal husbandry, analyses of reproductive performance data, milk record data, animal welfare, and calf management). The veterinarian could be indicated as a "very important," "important," "less important," or "not important" partner. Furthermore, the survey asked whether the veterinarian actually offers regular consultancy at the herd level (e.g., analysis and interpretation of herd record data).

The participants were asked about their needs for external consultancy with regard to 10 selected aspects of agriculture and herd management (e.g., feeding, control of fertility, metabolic diseases, lameness, and calf diseases). Response categories were "requested much better," "requested better," and "satisfied." Furthermore, participants were asked which data are regularly used for management decisions on the farms. Predetermined categories (breeding data from the FACB, data discussed in focus groups, milk record data provided monthly by the DHIS, and animal health data annually provided by the AAHS) were answered from "often," "sometimes," or "never." Finally, participants were asked to report their meeting or continuing education attendance frequency and how often they obtain animal health information from the Internet and professional journals ("often," "sometimes," "never").

\section{Statistical Methods}

Questionnaires in which fewer than $5 \%$ of the questions had been answered were excluded from the statistical analyses; likewise, doubled responses (controlled by IP number) were excluded. Data were analyzed using the SPSS statistical software (version 17, IBM Cooperation, Armonk, NY). Frequencies were tabulated for binary and categorical variables. Answers related to fields of consultancy and to concerns of the farmers were additionally stratified by milk yield of the farms ( $\geq 8,000 \mathrm{vs}$. $<8,000 \mathrm{~kg}$ of milk yield) and type of management (full-time vs. part-time). Frequencies were compared by chi-squared test where reasonable.

The relationship between farmer characteristics and the level of satisfaction with consultancy services was tested in an ordinal logistic regression model. The categories "requested much better," "requested better," and "satisfied" were used as the dependent variable and addressed the fields of consultancy (predictor variables). The selection of the farmer characteristics (factors $=$ questions of the general section) was done using a backward regression. The level of significance was set at $\alpha=0.05$.

\section{RESULTS}

\section{Survey Response}

A total of 1,620 farmers participated in the survey. Applying the previously described exclusion criteria, 602 surveys had to be withdrawn; therefore, 1,018 surveys were included in the final analysis. Some participants $(n=107)$ answered only the general section of the survey, resulting in 911 surveys that were analyzed for the specific section. The total response rate was $11.3 \%$ (10.1\% for the specific section).

\section{General Part}

The majority of the participants were male $(78.2 \%)$. Most participants were aged 30 to 50 y $(68.6 \%)$ or more than 50 y (21.6\%), respectively. Most of the farms $(63.8 \%)$ were managed on a full-time basis, reported a herd size of less than 20 cows $(54.0 \%)$, and had an average milk yield of 6,000 to $8,000 \mathrm{~kg} /$ lactation $(55.2 \%)$. The proportion of farms managed on full-time basis increased significantly with herd size. In farms with a herd size $<20$ cows, $44.4 \%$ were managed full-time, whereas 85.8 and $91.7 \%$ of herds with 20 to 50 cows and $>50$ cows were managed full-time, respectively. A summary of the answers is given in Table 1 .

\section{Farm Consultancy}

The farmers were asked to assess the importance of veterinarians and other consulting organizations for their farms with regard to animal health, feeding, breeding, and stable construction and animal husbandry (Table 2). All participants of this survey were member of the FACB and the regional DHIS. The proportion of members in the AAHS was $85.8 \%$, whereas $75.8 \%$ of them took part in at least one of the offered AAHS programs (Table 1 ).

With regard to animal health, the veterinarian was referred to most often as advisor (84.6\%), followed by the AAHS (31.9\%), and the regional DHIS (22.9\%). Consultancy services for feeding were mostly conducted by feeding enterprises $(51.0 \%)$, as well by veterinarians (20.4\%) and the DHIS (19.8\%). The majority of the farmers (46.4\%) declared that the FACB was an important partner for sire selection, but $22.7 \%$ of the farmers stated that they worked without any consultant in this area. The Chamber of Agriculture was the crucial contact for stable construction and animal husbandry (47.5\%; Table 2).

It was of interest whether differences between farm characteristics (milk yield, management) concerning consultancy existed; thus, the questions were stratified for these aspects. In some fields, farms managed 
Table 1. Responses to questions regarding the general part of the questionnaire $(\mathrm{n}=1,018)$

\begin{tabular}{|c|c|}
\hline Question & $\begin{array}{c}\text { Answer } \\
(\%)\end{array}$ \\
\hline \multicolumn{2}{|l|}{ Sex } \\
\hline Male & 78.2 \\
\hline Female & 21.8 \\
\hline \multicolumn{2}{|l|}{ Age (y) } \\
\hline$<30$ & 9.8 \\
\hline $30-50$ & 68.6 \\
\hline$>50$ & 21.6 \\
\hline \multicolumn{2}{|l|}{ Education } \\
\hline Agricultural school & 68.6 \\
\hline Agricultural diploma & 6.1 \\
\hline Other & 25.3 \\
\hline \multicolumn{2}{|c|}{ Participant of the AAHS ${ }^{1}$} \\
\hline Yes & 85.8 \\
\hline No & 13.1 \\
\hline In process & 1.8 \\
\hline \multicolumn{2}{|c|}{ Participant in programs of the AAHS } \\
\hline Yes & 75.8 \\
\hline No & 17.1 \\
\hline Unknown & 7.1 \\
\hline \multicolumn{2}{|l|}{ Farm management } \\
\hline Full-time & 63.8 \\
\hline Part-time & 36.2 \\
\hline \multicolumn{2}{|l|}{ Milk yield $(\mathrm{kg})$} \\
\hline$<6,000$ & 18.4 \\
\hline $6,000-8,000$ & 55.2 \\
\hline $8,000-10,000$ & 23.0 \\
\hline$>10,000$ & 3.4 \\
\hline \multicolumn{2}{|l|}{ Herd size (cows) } \\
\hline$<20$ & 54.0 \\
\hline $20-50$ & 40.1 \\
\hline$>50$ & 5.9 \\
\hline \multicolumn{2}{|l|}{ Main breed } \\
\hline Simmental & 60.3 \\
\hline Holstein & 16.4 \\
\hline Brown Swiss & 16.0 \\
\hline Other & 7.3 \\
\hline \multicolumn{2}{|l|}{ Housing system } \\
\hline Freestall & 50.6 \\
\hline Tiestall & 49.4 \\
\hline \multicolumn{2}{|l|}{ Veterinarian visits } \\
\hline$\geq 1 \times /$ wk & 9.9 \\
\hline$\overline{1} \times / 2 \mathrm{wk}$ & 29.6 \\
\hline $1 \times / \mathrm{mo}$ & 33.1 \\
\hline$<1 \times /$ mo & 27.4 \\
\hline
\end{tabular}

${ }^{1}$ AAHS $=$ Austrian Animal Health Service.

full-time relied on different partners for consultancy services than those managed part-time (Table 3). Fulltime farmers asked for advice from focus groups in matters related to feeding $(16.9$ vs. $11.1 \%, P=0.01)$ and stable construction and animal husbandry (11.6 vs. $7.6 \%, P=0.04)$ more often than part-time farmers. Differences between farms run full-time and part-time were also found in consultancy for sire selection $(51.2$ vs. $37.9 \%$ consultancy by FACB, $P=0.001 ; 18.6 \%$ vs. $13.3 \%$ consultancy by regional DHIS, $P=0.03$ ).

The comparison between high-yielding farms $(\geq 8,000$ $\mathrm{kg}$ of milk) and low-yielding farms showed significant differences in several aspects (Table 3). High-yielding farms were advised more often on sire selection by
FACB (61.3 vs. $41.0 \%, P=0.001$ ), whereas low-yielding farms relied more often on the veterinarian (13.1 vs. $7.4 \%, P=0.01$ ) and the regional DHIS (19.1 vs. $10.0 \%, P=0.001)$. More high- than low-yielding farms sought advice in focus groups with regard to animal health (22.7 vs. $10.8 \%, P=0.001)$, feeding (23.4 vs. $11.7 \%, P=0.001)$, and stable construction and animal husbandry (15.6 vs. $8.1 \%, P=0.001$ ), whereas lowyielding farms more often asked AAHS (7.2 vs. 3.3\%, $P=0.02)$ about issues related to stable construction and animal husbandry. With regard to feeding, highyielding farms consulted feeding enterprises more often than low-yielding farms ( 59.9 vs. $47.8 \%, P=0.01$ ), whereas the latter took advice more often from the regional DHIS (21.4 vs. $15.6 \%, P=0.04$; Table 3). Most farmers stated that milk records and reproduction data provided monthly by the regional DHIS $(70.3 \%)$ were frequently used as a basis for management decisions, along with data from FACB (20.4\%), AAHS (18.2\%), and data discussed in focus groups $(11.3 \%)$.

\section{Animal Health and Challenges to the Farmers, Role of the Veterinarian}

The issues relating to disease and health that most concerned ("very large problem" and "large problem") farmers were fertility, mastitis and high SCC, poor conception rate, lameness and claw problems, and calf diarrhea (Table 4). All answers were stratified by milk yield of the farms and kind of management. The analyses revealed differences only with regard to heat detection and calf diarrhea. Heat detection more often concerned high- than low-yielding farms (6.5 vs. 2.7\%, $P=0.03)$. Calf diarrhea was reported more often as a major problem by farms managed full-time than farms run part-time (9.6 vs. $4.3 \%, P=0.004)$ and by lowcompared with high-yielding farms (11.7 vs. $6.4 \%, P$ $=0.01$ ).

Besides their practical work, the local veterinarian was reported as a very important or important consultant for the farmers with regard to analysis of reproductive performance data $(46.2 \%)$, udder health $(37.2 \%)$, and animal welfare $(36.4 \%)$. Conversely, veterinarians were considered as "not important" consultants in matters of stable construction and animal husbandry, analysis of milk record data, and claw trimming $(64.9,52.8$, and $52.6 \%$, respectively; summarized in Table 5). Farmers stated that regular consultancy at the herd level was offered by $30.0 \%$ of the veterinarians, which was accepted by $82.6 \%$ of the farmers. Reproductive performance data $(73.7 \%)$, laboratory data $(64.0 \%)$, prevalence of diseases $(59.7 \%)$, milk record data $(54.0 \%)$, and BCS $(25.0 \%)$ were most frequently the content of this consultancy. 
Table 2. Responses as to who is consulting with the participants $(\mathrm{n}=1,018)$ with regard to animal health, feeding, stable construction (and animal husbandry), and sire selection (multiple answers possible)

\begin{tabular}{|c|c|c|c|c|}
\hline \multirow[b]{2}{*}{ Consultant } & \multicolumn{4}{|c|}{ Aspects of consultancy (\%) } \\
\hline & $\begin{array}{l}\text { Animal } \\
\text { health }\end{array}$ & Feeding & $\begin{array}{c}\text { Stable } \\
\text { construction }\end{array}$ & $\begin{array}{c}\text { Sire } \\
\text { selection }\end{array}$ \\
\hline Veterinarian & 84.6 & 20.4 & 7.9 & 11.6 \\
\hline Chamber of Agriculture & 10.5 & 17.6 & 47.5 & 1.2 \\
\hline Federation of Austrian Cattle Breeders & 11.6 & 8.1 & 2.0 & 46.4 \\
\hline Regional Dairy Herd Improvement Service & 22.9 & 19.8 & 1.9 & 16.7 \\
\hline Feeding enterprise & 7.0 & 51.0 & 0.8 & 0.2 \\
\hline Nobody & 5.8 & 12.6 & 17.8 & 22.7 \\
\hline Austrian Animal Health Service & 31.9 & 6.7 & 6.2 & 1.1 \\
\hline Focus group & 13.9 & 14.8 & 10.1 & 3.1 \\
\hline Private consultant & 4.2 & 13.1 & 7.7 & 4.4 \\
\hline Other & 3.1 & 3.3 & 2.8 & 2.8 \\
\hline University & 0.8 & 0.4 & 0.3 & 0.0 \\
\hline
\end{tabular}

\section{Demands for Consultancy}

Questions on the demands for improved consultancy did not refer to a defined group of consultants. The majority of the participants requested a much better or better consultancy regarding fertility $(64.7 \%)$, data analysis $(51.4 \%)$, feeding $(51.1 \%)$, and sire selection (51.1\%). Conversely, most farm managers felt that the current consultancies for stable construction, prevention of claw problems, calf diseases, metabolic disorders, mastitis, and vaccination programs were sufficient (Table 6). The results of the ordinal logistic regression analysis revealed that farmers who requested a much better consultancy with regard to fertility were more likely to be male and a participant in programs of AAHS, whereas a much better consultancy of data analysis and sire selection was more likely associated with farmers aged 30 to $50 \mathrm{y}$ and participants in programs of AAHS, respectively. An improved consultancy for feeding was requested more by farmers younger

Table 3. Responses as to who is consulting with the farmers $(\mathrm{n}=1,018)$ with regard to animal health, feeding, stable construction (and animal husbandry), and sire selection that were significantly different when comparing farms by kind of farm management or milk yield (multiple answers possible)

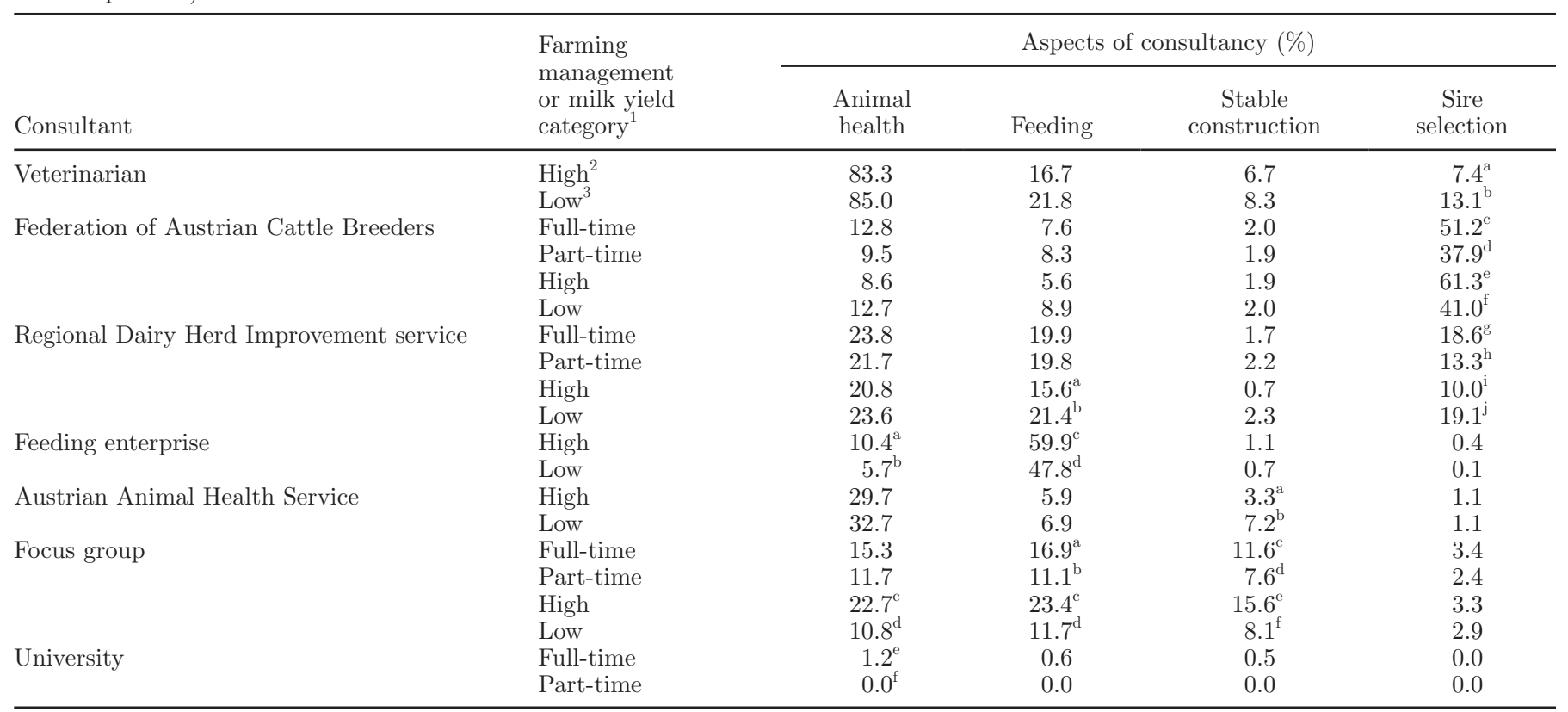

${ }^{\mathrm{a}-\mathrm{j}}$ Values with different superscripts differ $(P<0.05)$.

${ }^{1}$ Presented only for significant differences between full-time versus part-time managed farms and high- versus low-yielding farms.

${ }^{2} \mathrm{High}=$ herd average $\geq 8,000 \mathrm{~kg} /$ lactation.

${ }^{3} \mathrm{Low}=$ herd average $<8,000 \mathrm{~kg} /$ lactation. 
Table 4. Responses on the health issues and diseases that concern farm managers $(n=911)$

\begin{tabular}{lccrr}
\hline $\begin{array}{l}\text { Disease or } \\
\text { health issues }(\%)\end{array}$ & $\begin{array}{c}\text { Large } \\
\text { problem }\end{array}$ & $\begin{array}{c}\text { Moderate } \\
\text { problem }\end{array}$ & $\begin{array}{c}\text { Occasional } \\
\text { problem }\end{array}$ & $\begin{array}{c}\text { No } \\
\text { problem }\end{array}$ \\
\hline Fertility & 15.0 & 29.6 & 45.7 & 9.8 \\
Mastitis or high cell count & 13.0 & 22.1 & 53.7 & 11.3 \\
Poor conception rate & 8.5 & 28.2 & 47.6 & 15.7 \\
Lameness or claw problem & 8.2 & 18.8 & 51.6 & 21.4 \\
Calf diarrhea & 7.7 & 17.1 & 50.4 & 24.8 \\
Feeding of high-yielding cows & 7.3 & 18.4 & 41.8 & 32.4 \\
Heat detection & 5.6 & 17.5 & 39.4 & 37.5 \\
Metabolic disorders & 4.0 & 10.4 & 53.4 & 32.2 \\
Animal husbandry & 2.2 & 3.7 & 24.9 & 73.2 \\
Trichophytia & 2.0 & 3.1 & 29.8 & 69.5 \\
Respiratory diseases & 1.5 & 3.7 & 32.7 & 65.0 \\
Suckling weakness & 1.4 & 2.3 & 4.9 & 61.6 \\
Epidemic diseases & 1.4 & 1.0 & 0.2 & 91.6 \\
Others & 1.0 & 2.3 & 30.2 & 11.5 \\
Abortion & 0.7 & 1.4 & 21.5 & 66.7 \\
Diseases of gastrointestinal tract & 0.4 & 2.5 & 27.9 & 76.6 \\
Omphalitis & 0.2 & & 69.4 & \\
\hline
\end{tabular}

than $50 \mathrm{y}$, farms with a low milk yield, farms managed full-time, and herd sizes $<20$ cows. Table 7 summarizes the significant relationships between the farmer characteristics and the level of satisfaction.

\section{Transfer of Knowledge}

The respondents stated that professional journals $(79.5 \%)$ and the Internet $(65.8 \%)$ were frequently used as sources of information with regard to animal health. The Internet was often used by farmers of all age groups, with more participants in the group $<30 \mathrm{y}$ compared with older groups (73.0 vs. 59.2 and $51.4 \%$ in age groups $<30,30-50$, and $>50 \mathrm{y}$, respectively, $P$ $<0.05)$. The proportion of farmers that claimed not to use the Internet or professional journals was 12.6 and $3.3 \%$, respectively. Farmers attended at least one continuing education event per year organized by AAHS $(89.6 \%$; more than 2 events $=20.9 \%)$, the Chamber of Agriculture (74.4\%; more than 2 events $=11.4 \%$ ), and the regional DHIS or FACB $(74.0 \%$; more than 2 events $=11.4 \%$ ).

\section{DISCUSSION}

To reach a large number of farmers, the hyperlink of the online survey was distributed via e-mail to members of FACB. Cattle breeding in Austria is organized by FACB, with 22,670 dairy farms as members (in 2012). This represents approximately three-fourths of all Austrian dairy farmers (Grüner Bericht, 2012). Farmers were requested to take part in the survey by contacting them twice over a 3 -wk interval via e-mail and by explaining the importance of a contribution to improve consulting services in the future. It may be questioned whether the response rate could have been increased by providing any incentive or by additionally sending the survey by postal mail. The latter, however, could have resulted in double answers, both printed and online surveys, that cannot be controlled. Conversely, sending the hyperlink to the survey via e-mail only excluded farmers with no access to the Internet and farmers not familiar with the Internet. Therefore, the results of this study cannot be regarded as representative for all Austrian farmers. Despite these limitations, however,

Table 5. Responses as to the areas in which the veterinarian is an important, less important, or not important partner for the farmer $(\mathrm{n}=911)$

\begin{tabular}{lccc}
\hline Item $(\%)$ & Important & $\begin{array}{c}\text { Less } \\
\text { important }\end{array}$ & $\begin{array}{c}\text { Not } \\
\text { important }\end{array}$ \\
\hline Analysis of reproduction data & 46.2 & 25.8 & 28.0 \\
Udder health and milking & 37.2 & 31.5 & 31.4 \\
Animal welfare & 36.4 & 28.8 & 34.8 \\
Calf management & 33.3 & 31.9 & 34.8 \\
Feeding & 27.1 & 38.5 & 34.4 \\
Sire selection & 22.3 & 25.4 & 52.4 \\
Analysis of milk record data & 16.9 & 30.3 & 52.8 \\
Claw trimming & 13.9 & 33.5 & 52.6 \\
Stable construction or animal husbandry & 8.6 & 25.6 & 64.9 \\
\hline
\end{tabular}


Table 6. Responses as to the areas in which participating farmers $(\mathrm{n}=911)$ would welcome improved consultancy services or felt that present services were satisfactory

\begin{tabular}{lccc}
\hline & \multicolumn{3}{c}{ Stage of satisfactory (\%) } \\
\cline { 2 - 4 } Item & $\begin{array}{c}\text { Requested } \\
\text { much better }\end{array}$ & $\begin{array}{c}\text { Requested } \\
\text { better }\end{array}$ & Satisfied \\
\hline Fertility & 25.7 & 39.0 & 35.4 \\
Analysis of data & 14.4 & 37.0 & 48.6 \\
Feeding & 15.8 & 35.3 & 48.9 \\
Sire selection & 17.8 & 33.3 & 49.0 \\
Metabolism & 10.0 & 39.0 & 51.0 \\
Udder health & 11.4 & 34.7 & 53.9 \\
Calf health & 8.2 & 28.3 & 63.5 \\
Vaccination program & 6.6 & 21.6 & 71.8 \\
Lameness or claw diseases & 5.2 & 22.8 & 72.0 \\
Stable construction or technical facilities & 6.8 & 19.7 & 10.7 \\
Other & 0.7 & 0.6 & \\
\hline
\end{tabular}

the survey provides valid data on farmers' attitudes to the challenges and health issues on small- and mediumsized dairy farms. The response rate of $11.3 \%$ was lower than those described by others (Bergevoet et al., 2004; Caraviello et al. 2006; Russell and Bewley, 2011; Derks et al., 2013), but within the range of the survey by Heuwieser et al. (2010). The absolute number of 1,018 participants in this study, however, was greater than in most of the cited surveys.

Reproduction, animal health, and welfare are important for the economic success of dairy farms (Bertilsson et al., 1997); with this in mind, farm managers were asked to report who they consulted with on particular issues. In general, it can be assumed that all farmers use the services of almost all consultants, but we do not have data on the actual proportions. Thus, it must be noted that the (unknown) proportion of participants using the particular consultants could bias the interpretation when comparing the presented value of consultants. All farmers, however, have access to all services and consultants; therefore, the results of this survey give a good overview on engaged consultants. Most of the farmers responded that the veterinarian is an important partner with regard to aspects of animal

Table 7. Areas (predictor variables) in which respondents stated their stage of satisfactory with consultancy services (dependent variables $=$ requested much better, requested better, satisfied) that were significantly associated with farmers' characteristics ${ }^{1}$ (factors)

\begin{tabular}{|c|c|c|c|c|c|c|}
\hline \multirow[b]{2}{*}{ Predictor variable } & \multirow[b]{2}{*}{ Factor } & \multirow[b]{2}{*}{ Predictor $^{2}$} & \multirow[b]{2}{*}{ SE } & \multirow[b]{2}{*}{$P$-value } & \multicolumn{2}{|c|}{$95 \% \mathrm{CI}$} \\
\hline & & & & & $\begin{array}{l}\text { Lower } \\
\text { limit }\end{array}$ & $\begin{array}{l}\text { Upper } \\
\text { limit }\end{array}$ \\
\hline Fertility & $\mathrm{AAHS}^{3}$ & -0.339 & 0.144 & 0.018 & -0.621 & -0.057 \\
\hline \multirow[t]{2}{*}{ Lameness or claw problems } & Age $<30$ y & -0.571 & 0.278 & 0.040 & -1.116 & -0.026 \\
\hline & Herd size $<20$ & 0.679 & 0.284 & 0.017 & 0.122 & 1.235 \\
\hline \multirow{2}{*}{ Feeding } & Low-yielding & -0.426 & 0.159 & 0.007 & -0.737 & -0.115 \\
\hline & Herd size $<20$ & 0.556 & 0.280 & 0.047 & 0.007 & 1.106 \\
\hline Analysis of data & Age $<30$ y & -0.505 & 0.241 & 0.037 & -0.978 & -0.031 \\
\hline Sire selection & $\mathrm{AAHS}^{3}$ & -0.303 & 0.149 & 0.042 & -0.594 & -0.012 \\
\hline \multirow[t]{2}{*}{ Vaccination program } & Agricultural diploma & -0.741 & 0.361 & 0.040 & -1.448 & -0.034 \\
\hline & Holstein breeder & -1.684 & 0.772 & 0.029 & -3.198 & -0.170 \\
\hline Stable construction or technical & Age $30-50$ yr & -0.515 & 0.207 & 0.013 & -0.921 & -0.110 \\
\hline
\end{tabular}

${ }^{1}$ Farmer characteristics: sex, age group $(<30,30-50,>50 \mathrm{yr})$, education (agricultural school, agricultural diploma, others), farm-management (full-time, part-time), herd size $(<20,20-50$ cows, $>50$ cows), herd average milk yield (low $=<8,000$, high $=\geq 8,000 \mathrm{~kg}$ ), husbandry (tiestall, freestall), main breed (Simmental, Holstein, Brown Swiss, other), participant in AAHS programs (yes, no).

${ }^{2}$ Negative value $=$ the factor is predicting the dependent variable "requested much better"; positive value = the factor is predicting the dependent variable "satisfied."

${ }^{3}$ AAHS $=$ participant in programs of Austrian Animal Health Service. 
health. This is largely consistent with a recent study reporting that the veterinarian is an important and trustworthy advisor (Derks et al., 2013). In general, it seems likely that farmers rely largely on special consultants for the relevant topics. It is easy to understand for example, that consultancy service for feeding was most frequently asked from feeding enterprises. This result is consistent with reports by Caraviello et al. (2006), in which most farms suggested feed companies and nutritionists as crucial partners in feeding high-yielding cows. It has been described that dairy farms that consult feed advisory services have shorter intervals between calving and first insemination than other farms (Löf et al., 2007). Thus, it is not surprising that farmers primarily consult with feeding enterprises. Veterinarians, however, were the second-most frequent source of information on this topic. This underlines the fact that veterinarians need to have a certain level of knowledge in this field.

Although FACB was indicated as the most important partner for sire selection, it is interesting that a great number of farmers do not ask for consultancy for sire selection at all. It can be hypothesized that many farmers do not see a need for advice in this field because they have a lot of information from sire catalogs. Conversely, this might indicate that FACB could improve their offer or enforce their campaigns of information. In low-yielding farms, the veterinarian was more frequently consulted on sire selection than in high-yielding farms. This might indicate that high-yielding farms do not regard the veterinarian as a specialist in the field.

The results of this survey indicate that reproductive disorders, udder disease, lameness and claw problems, and calf diarrhea are of most concern to farm managers. This ranking should be interpreted with care because some fields cover a variety of aspects (e.g., fertility), whereas others are more specific (e.g., abortion). In general, however, the results are consistent with the study of Caraviello et al. (2006), in which AI rate, mastitis, and hairy heel warts and lameness were reported as the greatest animal health concerns. Our results also largely correspond to data in the literature on the reasons for culling in dairy farms (Etherington et al., 1996; Whitaker et al., 2000). It can be assumed that reducing the risk for involuntary culling is of interest to the farmer, although this was not queried in the present survey. The results of our study confirm that the areas farmers find most problematic or challenging are related to the most frequent diagnoses and treatments in Austrian dairy herds (Egger-Danner et al., 2012). Precise data on prevalence of the diseases, however, are not available and should be investigated in further studies.
In the present study, high-yielding farms reported more often than low-yielding farms that heat detection was a major problem. Although this finding only reflects the farmers' attitude and is not based on recorded data, other studies have shown that herds with high milk yield had shorter intervals from calving to first AI but had a greater number of inseminations per pregnancy, on average (Löf et al., 2007). It has been assumed that problems with reproductive performance are associated with an increased milk yield (Gröhn and Rajala-Schultz, 2000). Other studies, however, suggested that management factors and diseases have a stronger effect on reproduction than milk yield (Eicker et al., 1996). Herd size has also been described as an important factor related to estrus detection (Gordon, 2011), management decisions (Russell and Bewley, 2013), as well as prevalence of diseases (e.g., calf diarrhea; Torsein et al., 2011). Because the average herd size of most farms was fewer than 50 cows in the present study and variations in herd size were smaller than in other studies, this aspect was not analyzed in detail and should not be over-interpreted.

In the current study, farmers stated the need for better consultancy in the areas of prevention of fertility problems, analysis of herd record data, feeding, and sire selection. Although farmers automatically or regularly receive a great amount of data (e.g., milk record and fertility data; Iwersen et al., 2012), and the relevance of these data has been described in detail (Fetrow et al., 1990), it seems that many farmers are not familiar with interpretation of these data and, thus, feel they need improved consultancy in this field.

The ordinal regression model was used for predicting the response of "requested much better consultancy" in the fields of consultancy services. The results showed a significant relationship between some farmer characteristics and the level of satisfaction. This, however, has to be considered with caution, because responses could not be predicted by one single farmer characteristic and were influenced by various factors. The results showed that farmers that participated in programs of AAHS requested improved consultancy with regard to fertility and sire selection. Furthermore, farms managed full-time requested better consultancy on feeding more often than farms managed part-time. It is likely that both full-time farmers and those who participate in programs of AAHS are more interested in increasing the standard of their farms or introducing new knowledge and techniques. Another simple explanation would be that these farmers are not satisfied with current consultancy services provided by veterinarians, companies, and organizations. In the current study, farming on a full-time basis was correlated with herd size. Larger herd sizes were also reported by Young et al. (2010) 
to have an influence on the demand of farmers for improved consultancy.

For the veterinarians, the possible perception of a lack of competence in some fields could, to some extent, derive from the structure of veterinary practices in Austria. A recently published survey showed that two-thirds of Austrian cattle practices are single-person practices or a cooperation of 2 veterinarians (Atzmüller et al., 2012). It is unlikely that small practices can cover all the requirements of farms, including herd health services and consultancy. That survey showed also that the favored contents of continuing education for veterinarians cover similar fields as reported by the farmers in this study to be important for them (i.e., fertility, data analysis, feeding, and sire selection).

Another aspect of the survey concerned the transfer of knowledge. The sources of information (i.e., professional journals, Internet, and education events) can hardly be compared. Furthermore, the results should be interpreted with care because the survey could only be completed online (i.e., responses were obtained only from farmers who were familiar with the Internet). The Internet was indicated as a frequently used source of information; although this finding is in accordance with previous reports (Chase et al. 2006; Kensinger and Muller, 2006), another online questionnaire found that the Internet was of minor importance for farmers (Derks et al., 2013).

The majority of respondents stated that they attended educational events only once or twice per year. A previous survey also conducted in Austria revealed that veterinarians in farm animal practice attend, on average, up to 5 education events per year (Atzmüller et al., 2012). These results might indicate that veterinarians play an important role in transferring knowledge to the farms. The continuing education of farmers and veterinarians, together with keeping adequate records and analyzing data, are crucial factors for successful herd health management (Egger-Danner et al., 2012). Furthermore, as participating farmers named several consultants as important partners in various fields of animal health and herd management, it is obvious that good cooperation between dairy farm managers and external consultants is essential to reach the goals of successful dairy management.

\section{CONCLUSIONS}

Dairy farms need consultancy services in various aspects of animal health and agricultural issues. Such services represent an important tool for efficient herd management. The objectives of the online survey were to identify the areas that farmers most frequently perceive as challenging and to analyze farmers' attitudes to consultancy services provided by veterinarians and others. In accordance with previous work, reproductive disorders, udder disease, lameness, and calf diarrhea were the most challenging health problems. In addition to their practical work, veterinarians are important advisors with regard to animal health, but play only a minor role in aspects of stable construction and animal husbandry, analysis of milk record data, and claw trimming. The majority of farm managers would welcome improved consultancy services on matters related to fertility, data analysis, feeding, and sire selection.

\section{ACKNOWLEDGMENTS}

The authors acknowledge the support of the Federation of Austrian Cattle Breeders (Vienna, Austria) and cooperation with the regional Dairy Herd Improvement Service (Zwettl, Austria).

\section{REFERENCES}

Atzmüller, C., H. Pothmann-Reichl, M. Iwersen, and M. Drillich. 2012. Continuing education in cattle practice-Results of a survey. Tierärztl. Prax. Ausg. G Grosstiere Nutztiere 40(G):217-224.

Bergevoet, R. H. M., C. J. M. Ondersteijn, H. W. Saatkamp, C. M. J. van Woerkum, and R. B. M. Huirne. 2004. Entrepreneurial behaviour of Dutch dairy farmers under a milk quota system: Goals, objectives and attitudes. Agric. Syst. 80:1-21.

Bertilsson, J., B. Berglund, G. Ratnayake, K. Svennersten-Sjaunja, and H. Wiktorsson. 1997. Optimising lactation cycles for the highyielding dairy cow. A European perspective. Livest. Prod. Sci. 50:5-13.

Caraviello, D. Z., K. A. Weigel, P. M. Fricke, M. C. Wiltbank, M. J. Florent, N. B. Cook, K. V. Nordlund, N. R. Zwald, and C. L. Rawson. 2006. Survey of management practices on reproductive performance of dairy cattle on large US commercial farms. J. Dairy Sci. 89:4723-4735.

Chase, L. E., L. O. Ely, and M. F. Hutjens. 2006. Major advances in extension education programs in dairy production. J. Dairy Sci. 89:1147-1154.

Derks, M., L. M. A. van de Ven, T. van Werven, W. D. J. Kremer, and H. Hogeveen. 2012. The perception of veterinary herd health management by Dutch dairy farmers and its current status in the Netherlands: A survey. Prev. Vet. Med. 104:207-215.

Derks, M., T. van Werven, H. Hogeveen, and W. D. J. Kremer. 2013. Veterinary herd health management programs on dairy farms in the Netherlands: Use, execution, and relations to farmer characteristics. J. Dairy Sci. 96:1623-1637.

Drillich, M., N. Klever, and W. Heuwieser. 2007. Comparison of two management strategies for retained fetal membranes on small dairy farms in Germany. J. Dairy Sci. 90:4275-4281.

Egger-Danner, C., B. Fuerst-Waltl, W. Obritzhauser, C. Fuerst, H. Schwarzenbacher, B. Grassauer, M. Mayerhofer, and A. Koeck. 2012. Recording of direct health traits in Austria-Experience report with emphasis on aspects of availability for breeding purposes. J. Dairy Sci. 95:2765-2777.

Eicker, S. W., Y. T. Gröhn, and J. A. Hertl. 1996. The association between cumulative milk yield, days open, and days to first breeding in New York Holstein cows. J. Dairy Sci. 79:235-241.

Etherington, W. G., M. L. Kinsel, and W. E. Marsh. 1996. Relationship of production to reproductive performance in Ontario dairy cows: Herd level and individual animal descriptive statistics. Theriogenology 46:935-959.

Fetrow, J., D. McClary, R. Harman, K. Butcher, L. Weaver, E. Studer, J. Ehrlich, W. Etherington, W. Guterbock, D. Klingborg, J. Re- 
neau, and N. Williamson. 1990. Calculating selected reproductive indices: Recommendations of the American Association of Bovine Practitioners. J. Dairy Sci. 73:78-90.

Gordon, P. 2011. Farm animal practice: Oestrus detection in dairy cattle. In Pract. 33:542-546.

Gröhn, Y. T., and P. J. Rajala-Schultz. 2000. Epidemiology of reproductive performance in dairy cows. Anim. Reprod. Sci. 6061:605-614.

Grüner Bericht. 2012. Agrarstrukturen und Beschäftigung. Agrarstruktur in Österreich. Accessed Jun. 10, 2013. http://www. gruenerbericht.at/cm2/index.php.

Heuwieser, W., M. Iwersen, J. Gossellin, and M. Drillich. 2010. Short communication: Survey of fresh cow management practices of dairy cattle on small and large commercial farms. J. Dairy Sci. 93:1065-1068.

Iwersen, M., D. Klein, and M. Drillich. 2012. Using on-farm records to evaluate the reproductive performance in dairy herds. Tierärztl. Prax. Ausg. G Grosstiere Nutztiere 40(G):264-274.

Jansen, J., C. D. M. Steuten, R. J. Renes, N. Aarts, and T. J. G. M. Lam. 2010. Debunking the myth of the hard-to-reach farmer: Effective communication on udder health. J. Dairy Sci. 93:12961306.

Kensinger, R. S., and L. D. Muller. 2006. Major advances in teaching dairy production. J. Dairy Sci. 89:1155-1162.

Kielland, C., E. Skjerve, O. Østerås, and A. J. Zanella. 2010. Dairy farmer attitudes and empathy toward animals are associated with animal welfare indicators. J. Dairy Sci. 93:2998-3006.
Kristensen, E., and C. Enevoldsen. 2008. A mixed methods inquiry: How dairy farmers perceive the value(s) of their involvement in an intensive dairy herd health management program. Acta Vet. Scand. 50:50

LeBlanc, S. J., K. D. Lissemore, D. F. Kelton, T. F. Duffield, and K. E. Leslie. 2006. Major advances in disease prevention in dairy cattle. J. Dairy Sci. 89:1267-1279.

Löf, E., H. Gustafsson, and U. Emanuelson. 2007. Associations between herd characteristics and reproductive efficiency in dairy herds. J. Dairy Sci. 90:4897-4907.

Noordhuizen, J. P. T. M., and J. H. M. Metz. 2005. Quality control on dairy farms with emphasis on public health, food safety, animal health and welfare. Livest. Prod. Sci. 94:51-59.

Russell, R. A., and J. M. Bewley. 2011. Producer assessment of dairy extension programming in Kentucky. J. Dairy Sci. 94:2637-2647.

Russell, R. A., and J. M. Bewley. 2013. Characterization of Kentucky dairy producer decision-making behavior. J. Dairy Sci. 96:47514758

Torsein, M., A. Lindberg, C. H. Sandgren, K. P. Waller, M. Törnquist, and C. Svensson. 2011. Risk factors for calf mortality in large Swedish dairy herds. Prev. Vet. Med. 99:136-147.

Whitaker, D. A., J. M. Kelly, and S. Smith. 2000. Disposal and disease rates in 340 British dairy herds. Vet. Rec. 146:363-367.

Young, I., A. Rajić, S. Hendrick, S. Parker, J. Sanchez, J. T. McClure, and S. A. McEwen. 2010. Attitudes towards the Canadian quality milk program and use of good production practices among Canadian dairy producers. Prev. Vet. Med. 94:43-53. 